\title{
EDITORIAL
}

\section{Intensive Care Medicine: onwards and upwards}

\author{
Elie Azoulay* ${ }^{*}$ \\ (c) 2018 Springer-Verlag GmbH Germany, part of Springer Nature
}

Six years ago, when I had the honour of being chosen to be editor-in-chief of Intensive Care Medicine, I discovered that I had been charged with piloting an ESICM supercraft along the critical care highway that plunges through the medical publishing galaxy. The specific rules, speed limits, commitments, and responsibilities co-existing with vast uncharted spaces created intense pressures of a type I had not experienced previously. Although strongly supported by the editorial board, the editor-in-chief manages most of the journal alone, continually mediates conflicts, scrutinises every decision, and issues reminders far and wide every day. Goals developed by the editorial board must be broadcast clearly and regularly to ensure a harmonious channelling of energies. Simultaneously, one's usual commitments, far from being temporarily put on hold, expand: editors-in-chief of major journals are asked to teach and speak about the editorial processes, such as peer review and editorial discussions, which are designed to winnow the most rigorous and currently relevant science out of a vast body of usually thoughtful and inspired research. Medical journals are often perceived as working behind closed doors to apply enigmatic procedures they have no wish to disclose. The editor-in-chief is thus seen as holding the keys to the mystery of how to get published.

These 6 years of busy days and brief nights have been one of the greatest challenges of my professional life. They have also provided me with an unexpectedly rich opportunity to read, learn, and debate. My perspective has expanded, yet the horizon line has remained in place: outstanding clinical research requires not only roots in clinically relevant questions but also a strong

*Correspondence: elie.azoulay@aphp.fr

Médecine Intensive et Réanimation, APHP, Hôpital Saint-Louis, 1 avenue Claude Vellefaux, 75010 Paris, France methodological trunk branching into sound and creative interpretations.

ICM has changed substantially over the last few years. All the changes-and only those changes-that I presented to the search committee on 22 March 2012 have been implemented. New submission tracks have boosted the journal's usage and reach. The number of submissions has increased by $70 \%$. Simultaneously, the ESICM has grown in size, scientific diversity, and cultural wealth. The topics covered by ICM are broader. ICM authors, readers, reviewers, and editors come from all over the world and have contributed to define the best standard of care in various settings. Despite being the official journal of the ESICM, ICM is indisputably international. Extraordinary efforts by reviewers and editors shortened the submission turnover time: decisions were made within 2 days when manuscripts were not sent out for review, 17 days when a review was followed by rejection, and 11 days when a minor or major revision was requested. The decision was given within 3 weeks overall for $90 \%$ of submissions and within 5 days on average for 7-day profile submissions. The numbers of accessed and downloaded articles have increased, as have the citations, which now make ICM a high-impact factor journal and the leading publication focussing solely on critical care.

This success is built on a foundation of brilliant authors striving to address relevant clinical questions by applying appropriate methods, skilled reviewers intent on guiding authors towards improving their work, and gifted editors dedicating their valuable time to share their hard-earned wisdom. But first, my warmest thanks go to the four astounding deputy editors who gave themselves unreservedly to $I C M$ and whose charisma and vision attracted the best of what ICM has published: Giuseppe Citerio, Samir Jaber, Anders Perner, and JeanFrançois Timsit. I am indebted also to Anders Aneman, Yaseen Arabi, Jan Bakker, Matteo Bassetti, Dominique

\section{实 Springer}


Benoit, Maurizio Cecconi, Deborah Cook, Randy Curtis, Michael Darmon, Gordon Doig, Glenn Hernandez, Margaret Herridge, Morten Hylander Moller, Michael Joannidis, Ignacio Martin-Loeches, Laurent Papazian, Marc Peters, Katerina Rusinova, Miet Schetz, Marcus Schultz, Pierre Singer, Martin Smith, Marcio Soares, Dan Talmor, Antoni Torres, Theodoros Vassilakopoulos, and Antoine Veillard-Baron. Your contribution to ICM has been monumental and the quality of your work impressive. Thanks to all of you, ICM now receives submissions of the highest quality. Quality editors attract quality papers. Special thanks go also to our annual guest editors Khalid Abidi, Jigi Divatia, Sharon Einav, Elisa Estensoro, Satoshi Gando, and Penglin Ma, who have elevated the profile of $I C M$ in their parts of the world. I will always be deeply grateful to our dedicated board of reviewers whose analyses were not only of remarkable quality but also provided within a timeframe consistent with our rapid turnover. And finally, I, and ICM, owe an extraordinarily deep debt of gratitude to Martin Lavillonnière, our smart, patient, visionary, and steadfast managing editor. There is no question that without Martin, ICM would not be what it is today.

I am grateful to the ESICM for giving ICM a place of prominence at their conferences and in their weekly emails, responding positively to all our requests, and striving to reward and recognize our readers, authors, reviewers, and editors. Also, the ESICM encouraged their sections to produce high-quality statements and to give priority to ICM for the best productions, thereby strongly supporting our journal.

I am happy that Professor Giuseppe Citerio is now editor-in-chief. Giuseppe knows ICM inside out and has contributed greatly to build the $I C M$ we have today. Working with him for 6 years, I have been impressed by his dedication both to $I C M$ and to the richness and diversity of the critical care community. His open mind looks to the future and to the opportunities it holds for further changes that will continue to improve our journal. The handover has unfolded with spontaneity and efficiency in equal measure. Giuseppe, together with the other deputy editors and editors, has helped ICM to better represent our community and to foster and disseminate our research. In a few weeks, with the growing impact factor, ICM will become one of the TOP 100 medical journals (among almost 12,000 indexed journals). I am convinced, nevertheless, that ICM has not yet fulfilled $50 \%$ of its potential. The journal must therefore continue onwards and upwards. One obvious area for improvement is identification of the best work among the many excellent submissions via initial manuscript selection, peer review, and internal discussion. Another more innovative task would consist in offering editing and rewriting of accepted manuscripts by professionals with expertise in science, English language, and ICM style. ICM needs professional medical writers and editors who thoroughly revise all papers before they are released in print and online. Thus, the future must target both substance and form.

The last 6 years have been 2190 (yes, that is $6 \times 365$ ) days populated with 11,000 papers, 1100 pre-submission inquiries, 550,000 emails, 25,000 text messages, hundreds of Skype meetings with authors and editors, and hundreds of slides promoting ICM throughout the world. I must admit it was a struggle, escalating at times to battle heights, albeit without the hostility: for I have never felt so rewarded and honoured. I am lucky to have very good reasons to make saying goodbye so hard.

Thank you.

Received: 7 December 2018 Accepted: 8 December 2018 Published online: 18 December 2018 